\title{
Meditations on the Informationization in the Army
}

\author{
Jin-Guang Liu, Xi Chen \\ Border Control College of Public Security, Guangzhou, 510663 China \\ E-mail: 13149377788@163.com,1805756081@qq.com
}

\begin{abstract}
As a modern dominant force, information technology construction in the army is the core part and brace in the army modernization. And its essence is a process includes an extensive use of advanced information technology and equipment in the military field, the effective development and use of information related to national security interest's resources, comprehensive development of combat. Also, it includes the development and adoption of information technology and military equipment, the establishment of national defense information infrastructure, the development of information technology weapons and equipment, the creation of military doctrine and organizational system and information technology to adapt, the establishment meet the information needs of management, education and training system, methods and mechanisms and other aspects of content. This paper analyzes the current army information construction situation, focusing on the application of information technology achievements in army building, and raised profound meditation towards information technology problems in the army.
\end{abstract}

Keywords-Army informationization; Modernization; Army construction

\section{I .SEIZE THE TENDENCY OF INFORMATIONIZATION CONSTRUCTION}

The essence of the information technology construction in the army is a process, which adopts advanced information techniques and equipment in the military field; effectively explore and utilize information resources related to national security interests and comprehensively develop battle capability. Information technology construction includes the development and adoption of information technology and military equipment, the establishment of national defense information infrastructure, the development of information technology weapons and equipment, the creation of military theories and organizational system which conform to informationization, and management, education and training system, methods which established to meet the needs of informationization.

The wars in the future are not only one with the concept of overall situation and system, but one emphasized on details. Thus, in the information construction process, it is necessary to track the forefront, focusing on innovation, and to grasp the key points and trends of information technology. Only in that way can we consolidate the basis of information construction.

Firstly, the information construction in the army should be changed from the hardware development to digital existence. The construction must focus on the spot that's from radar, satellites, computers and other hardware infrastructure in the industrial era to software infrastructure. Because future wars not only to deal with the enemy's forces and weaken the enemy industrial base, but also to destroy its information system. Battle methods will also be focused on information warfare, precision warfare, controlling warfare, stealth warfare and so on. Although the misery of war still exists, the battlefield will be extremely transparent. Front sensors, space satellites will transmit constantly a variety of intelligence information to the computer, which can even be shown on the screen in command post simultaneously, all soldiers can obtain the information in the meantime. So they can have a clear access to the positions, postures and movements of both sides. In addition, the degree of integration of information warfare has been greatly increased; especially rely more on information flows. Therefore, in the process of information construction, the formation of warfare construction, command and control information system construction and other digital existence of the combat system must be placed in a very important position. And continue to increase investment in information security projects, to ensure that Information systems can work normally in the case of enemy invasion, and to accomplish the conversion from the hardware development to digital existence as soon as possible.

Secondly, information technology construction in the army should change from dispersed ensemble to system integration. Information has become the key of battle capability. A variety of information technology equipment universal network has formed a huge information system. Battlefield has shown trends in networking and intelligent. But compared with developed countries, the army's information system has not completely got rid of the dispersion composition. Interconnection between the branches of the military is still relatively difficult, and it hasn't met the requirements of comprehensive integration. Construction of the fragmentation of this situation will inevitably result in a one-sided operation of information systems and information flow discrete. And situation like this has caused difficulties for the implementation of cross-level, cross-arms "super union" war of information acquisition, transmission and processing. The future war increasingly presents a system-to-system confrontation. Therefore, only by combining the command, intelligence and reconnaissance, electronic information networks and integrated information technology weapons and equipment into a scientific entity and carry on a full range of comprehensive integrated construction can we really enhance the combat capabilities 
and combat effectiveness of the army.

\section{II .EXPLORE DEEPLY ON THE INFORMATIONAL INFLUENCE ON THE MILITARY SYSTEM}

Information technology construction in the military field is not caused by a local, a certain level of change, but the overall change. The reform contains plenty of aspects: From the army's weapons and equipment to the organizational structure, education and training, the strategy and tactics, from material factors to the human factor, from hardware to software, it will lead to profound changes in the military field, as well as to the army's military system.

\section{A. Structurally: Building New Military Architectures}

Information technology construction is a military revolution. The force of change will be applied to varying degrees among military system. There are usually two forms of structural changes in the military system. Firstly, according to the new principles and forms, the military elements of the original field are to be re-combined to form a new internal relation. In this case, there is no fundamental change the original elements. But through structural adjustment, their position in the military system, the operation mode and the relationship has changed, which endow them with a new quality. Secondly, it is needed that the new military elements are permeated into the military system to the frame structure being and combining it with the original elements and lead to the transformation of the original elements, hereby affecting the formation of the military system fundamentally.

\section{B. Functionally: Gather and Release New Energy}

Information technology construction is a technological revolution, when the technological revolution make material and technological foundation of army and war quality change, the military began to grow a new potential energy. But within the framework of the existing military system, the potential growth is in a fragmented or constrained state. Since the old military system is the basis of the technology before the material is formed, this is technically impossible to provide a new and an appropriate environmental condition for growing. On the contrary, it will cause some resistance. Without reshaping the military system, it is difficult to put together new potential in the field of military effectively and be fully released. They can only be dispersed, and exert themselves singly, and can even be restricted and repressed, but not fully demonstrate its effectiveness. Effectively contributed to the military field in hidden form of energy produced by the potential to really form transformation, which is the function of the new era of information technology. It is also a significant performance reflected that the new military system is superior to the old one.

\section{Systematically: To Promote Comprehensive And Coordinated Development.}

Any revolutionary changing in the field of military is the three organic unities of military technology, military doctrine and military organizational structure. Although the first impetus comes from advances in military technology, but in general, mostly at the beginning of this progress than in the force in the form of an impact on the armed forces and war, the military's initial reaction to it also tends to be spontaneous, emotional and intuitive. In order to make the new military technology show in with the new military doctrine and the new system of combining military organization of all revolutionary significance, it must form an inherent operational mechanism in the military system, the spontaneous and passive process transferred into conscious and dynamic process.

\section{STRENGTHEN INFORMATIZATION CONSTRUCTION}

To speed up the construction of information army, it should avoid "short board" effect, it is necessary to strengthen the overall information system.

\section{A. To Improve Information Organization System}

Information technology construction is a universal, urgent and mandatory project, involving many frontier and super cutting-edge issues and all aspects of the work. It brought a strong impact on the traditional concepts and models. We need to achieve the unity of the data link with the agency chain on the physical preparation. It should establish an integrated authority and operational mechanism of information fusion, in order to solve the problems of information use and information sharing. In addition, the information acquisition, transmission, processing, use, distribution, and other related elements compiled into a whole. And to solve the problem use of information and command control, the data link physical changes on the command and control chain mechanism. This requires the establishment of an authority as quickly as possible, integrated organizational system for overall planning and scientific guidance in order to make this massive project quickly expand,and move forward systematically.

\section{B. To Strengthen the Information Policy System}

With the acceleration of military information technology, various units and departments are actively exploring the study and method of the department of information technology, shows the prosperous situation. But blindly carrying on one's own business is bound to cause the system fragmentation and it not achieve "hit through", "anti-pass" and "joint pass" purposes. In 1994, the US Army set up a working group of information technology professional, relying on its advanced laboratory equipment and training centers to develop a system of standards, processing structure, transmission frame, man - machine interface standards, etc., but because the services are acting on their own, resulting in the huge system beginning incompatible and causing a huge waste. In the process of information construction, we must learn from the US military that they had dispersed design become an obstacle to the construction. In the beginning of the construction, we should strengthen development policy system. Firstly, establish unified information standards in the army. Forces of information resources and applications software are able to be shared; it must comply with uniform technical standards and norms. 
Secondly, establish sound policies, norms and institutional system. Forces of information need to enrich. To comply with a unified standard based on the information, strict implementation of a unified standard need to observe supervision and inspection regulations. In addition, it is of highly demand to establish sound policies, norms, institutional system or the information security needs. Thirdly, explore military information technology for sustainable development mechanisms and the development of research. Information technology in the army must have scientific proof, overall planning, to joint operations with the overall demand for traction. Drawing generation platform, the development model multigenerational load should avoid chaotic construction, system inefficiencies and low equipment efficiency problems.

\section{To Deepen the Information Technology System Construction.}

From different angles, to give a description of the technical system of army information is different. From the perspective of management, information technology system in the army can be divided into two levels: infrastructure layer and application layer. The infrastructure layer mainly refers to the hardware infrastructure and soft resources infrastructure. The hardware infrastructure includes those facilities playing an important role in the information construction such as computer, network. The soft resources infrastructure includes norms and standards of army information, for operations, training and management of the database and on this basis. The application layer mainly refers to a variety of applications based on network. The armies of the hardware model are not uniformed and software development is not standardized. The problem that standards are not unified still exists, which restricted the system overall performance of the play. But the war system function depends on the overall stability of the whole system and balance. The stability and reliability of the system is affected by the system between the combining part and connection point and joint point reliability. But many are not unified, is bound to cause system instability. In addition, the effectiveness of military system integration is not decided by a single platform and a single action, but by various platforms and the integration of the overall action ability of the system together with the decision. Therefore, in the process of information construction, we have to be sure to strengthen technical system and break the sectarianism to seek the function of the system, function and structure and to give full play to the overall efficiency of the system.

\section{Attach much importance to information technology training system.}

The primary goal of informatization training system is to make the army become qualified builders of users. Information construction processes are described as building a highway. First it is needed to build a road (highway network infrastructure), and then a car (the construction platform), car loading (to provide information), a well-trained driver (Information Management), traffic regulations (corresponding regulations). Although each different person play a different role in the position in this series of work and the entire series of functional requirements are also different. However, if we lack the basic understanding to the expressway, no one would built and make good use of the highway. So it is the same with the basic information construction units, especially with the information war is approaching. The information quality and information ability has become one of important part forming the battle capacity. So improving the level of informatization construction and information quality and information ability, we must strengthen the construction of information technology training system.

\section{REFERENCES}

[1] Wang Hua, Consideration on Promoting the Scientific Development of CAPF Information Construction, Science \& Technology Economy Market, 2011.

[2] Huo Rui, The Consideration on Promoting CAPF Information Construction, National Defense, December 2005.

[3] Xia He. Driven by the Information Construction, to Improve the "Four Basics" Construction in CAPF, National Defense, August 2005.

[4] Yao Yuanlin, Chen Xin. Several Ideas about Promoting Quickly the Information Construction in Grassroot CAPF, Military Communication Acadamics, 2006.

[5] Peng Xiaoli. An Analysis of the Current Situation of Military Information Construction, Technology Wind, September 2012. 